Reprod. Nutr. Dévelop., 1988, 28 Suppl. n 1, 69-70

\title{
La chitine synthase de Neocallimastix frontalis, un marqueur enzymatique de la biomasse fongique
}

L. GAY, M. HEBRAUD, V. GIRARD, M. FĖVRE

Laboratoire de Différenciation Fongique, C.N.R.S. U.A. 1127, Université Lyon I, 43, boulevard du 11-Novembre-1918, F-69622 Villeurbanne, France.

Summary. Chitin synthase responsible for chitin synthesis in the fungal cell wall was detected in the actively growing mycelium of Neocallimastix frontalis and was associated with the cell membrane. From a linear relation between enzyme activity and protein content of the cultures, this enzyme proved to be useful to assess the biomass of rumen fungi.

La chitine synthase a été isolée à partir d'un grand nombre de champignons (1) où elle joue un rôle primordial dans la biosynthèse de la paroi cellulaire (2). L'activité de cet enzyme qui est liée au développement des champignons peut donc être un marqueur physiologique utile pour estimer la croissance des champignons du rumen dont la quantification est malaisée $(3,4)$.

Matériel et méthodes. Neocallimastix frontalis (isolé du rumen de mouton) est cultivé à $39^{\circ} \mathrm{C}$ sur milieu liquide (5) et le mycélium est récupéré par centrifugation $(8000 \times g, 10 \mathrm{~min})$. Après homogénéisation avec un broyeur à

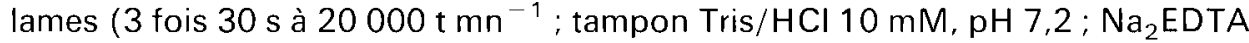
$2 \mathrm{mM}$ ) le broyat $(\mathrm{CH})$ est fractionné en une fraction pariétale (CWF : $1000 \times g$, $10 \mathrm{~min}$ ) une fraction membranaire (MMF : $48000 \times \mathrm{g}, 30 \mathrm{~min}$ ) et un surnageant (SF). L'activité chitine synthase de ces extraits est mesurée après $40 \mathrm{~min}$ d'incubation à $32^{\circ} \mathrm{C}$ d'un milieu réactionnel $(200 \mu \mathrm{l})$ contenant $0,5 \mathrm{mM}$ UDP

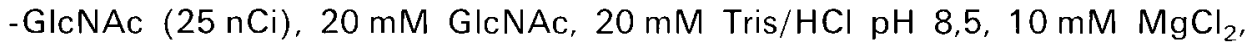
$2,5 \mu \mathrm{g}$ de trypsine et $50 \mu \mathrm{l}$ d'enzyme (100 à $150 \mu \mathrm{g}$ de protéine).

Résultats et discussion. La distribution de l'enzyme entre CWF et MMF peut varier en fonction du broyage et de l'âge de la culture mais en moyenne $65 \%$ de l'activité est associée avec CWF et $35 \%$ avec MMF, alors qu'aucune activité n'est mesurable dans SF. Un broyage plus important diminue le pourcentage d'enzyme membranaire qui reste lié aux parois mais l'activité spécifique de l'enzyme, mesurée en nmol d'UDP-GIcNAc incorporée par minute et par mg de protéine, est alors fortement diminuée. L'enzyme se trouve essentiellement sous forme zymogène (activité $\times 5$ par le traitement à la trypsine) et présente des propriétés comparables à celles observées chez les autres champignons (2). Le pH optimum de la réaction se situe vers $\mathrm{pH} 8,5$ à une température de $32^{\circ} \mathrm{C}$. L'incorporation du substrat (UDP-GIcNAc) reste linéaire pendant plus de $60 \mathrm{~min}$ et la cinétique de la réaction donne un $K_{\mathrm{m}}$ apparent de $2 \mathrm{mM}$. La polyoxine $D$ joue le rôle d'inhibiteur compétitif de la réaction avec un $K_{1}$ de $4 \mu \mathrm{M}$. L'ion bivalent $\mathrm{Mg}^{2+}$ est nécessaire à l'action de l'enzyme qui est stimulé par $20 \mathrm{mM}$ GlcNAc. 
La figure 1 montre que l'activité spécifique de l'enzyme augmente avec la croissance du mycélium, mais dès que la culture atteint la phase stationnaire (4 jours de culture) l'activité chitine synthase chute rapidement indiquant que cet enzyme est directement lié à la croissance active du mycélium.
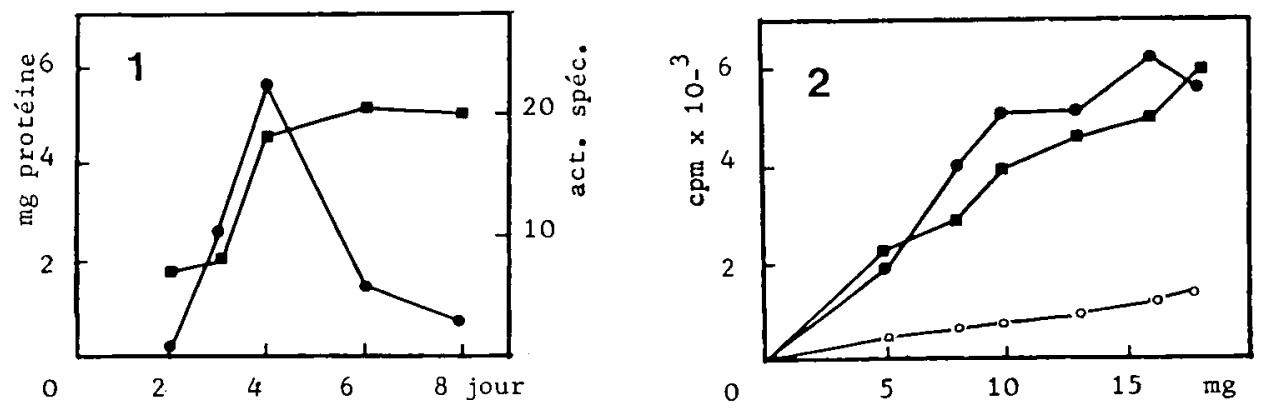

FIG. 1. - Croissance du champignon (口) en $\mathrm{mg}$ de protéine pour $50 \mathrm{ml}$ de culture et activité

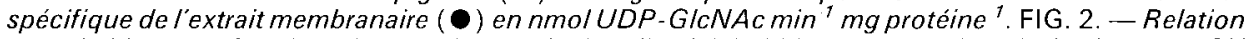
entre la biomasse fongique (en $\mathrm{mg}$ de protéine) et l'activité chitine synthase (cpm) des fractions $\mathrm{CH}$ (O), CWF (ם) et MMF (O).

Avec des extraits provenant de cultures de même âge mais contenant des quantités différentes de mycélium (fig. 2) il y a une relation linéaire (surtout avec $\mathrm{CH}$ ) entre l'activité enzymatique de l'extrait et le contenu protéique de la culture. D'après ces courbes, il est donc possible de calculer la quantité de mycélium contenu dans une culture. Ainsi, une expérience test avec une culture âgée de 3 jours donne une valeur mesurée de $10,5 \mathrm{mg}$ de protéine alors que la valeur calculée d'après les courbes est de 11 à $13 \mathrm{mg}$ de protéine.

En utilisant des conditions standard on peut donc, grâce à l'activité chitine synthase d'un extrait, mesurer la quantité de mycélium contenu dans une culture de champignon du rumen avec une marge d'erreur inférieure à $10 \%$. De plus ce dosage ne prend en compte que le mycélium vivant alors que le dosage de chitine (Akin, 1987) peut concerner du mycélium inactif ou des contaminants. Toutefois, avant de transposer cette technique à la mesure d'une croissance fongique dans le rumen, il faudra connaître l'activité chitine synthase des autres champignons du rumen et déterminer dans quelle mesure un système microbiologique aussi complexe que du rumen peut influer sur le dosage.

(1) Cabib E., 1981. Encyclopedia of Plant Physiology, 13 B, 395-415.

(2) Gooday G. W., Trinci A. P. J., 1980. The Eucaryotic Microbial Cell, 207-251, G. W. Gooday, D. Lloyd et A.P. J. Trinci ed., Cambridge Univ. Press.

(3) Akin D. E., 1987. Appl. env. Microbiol., 53, 1955-1958.

(4) Lowe S. E. et al., 1987. J. gen. Microbiol., 133, 1815-1827.

(5) Lowe S. E. et al., 1985. J. gen. Microbiol., 131, 2225-2229. 